\title{
Disseminated skin lesions in a patient with AIDS
}

\author{
A Visser, A van de Vyver, A Essop, CE Nel \\ Adele Visser, Department Clinical Pathology, University of Pretoria, National Health Laboratory Services, Tshwane Academic Division. \\ Annemarie van de Vyver, Department Internal Medicine, Kalafong Hospital, University of Pretoria. \\ Ahmed Essop, Department Dermatology, University of Pretoria. \\ CE Nel, Department Anatomical Pathology, University of Pretoria, National Health Laboratory services, Tshwane ACADEMIC Division.
} Correspondence to: adele.vis@up.ac.za

Patients with advanced HIV-1 disease can present with a vast array of opportunistic infections. Not only is the spectrum of disease more diverse, but the spectrum of presentation can vary significantly from what is expected. In this case report we describe a patient with advanced HIV-1 disease presenting disseminated skin lesions and haematological abnormalities. Upon further investigation, a probable diagnosis of disseminated histoplasmosis was established. The patient was subsequently treated with oral itraconazole and showed marked haematological and clinical improvement within six weeks of therapy. Histoplasmosis is an opportunistic infection endemic to South Africa and, like most opportunistic infections, can present with a myriad of clinical features which can complicate early diagnosis. Although not as prevalent as in other parts of the world, it should always be considered as part of the differential diagnosis, especially among severely immunocompromised individuals.

(P) Peer reviewed. (Submitted: 2010-11-09. Accepted: 2011-01-11.) ๑ SAJEI South Afr J Epidemiol Infect 2011;26(4)(Part II):285-287

\section{Case report}

A 33-year-old HIV-1-infected male patient, with a CD4+ T cell count of $108 \mathrm{cell} / \mathrm{mm} 3$, presented with a three-month history of asymptomatic cutaneous lesions of the face and neck. The patient had a nodular infiltration, prominent in the centre of the face, with enlargement of the upper lip, and relative sparing of the temporal area and ears. Only a few of these lesions were umbilicated, and there were no erosions or ulcers (Figure 1a and b). He had no constitutional symptoms and looked healthy otherwise. The patient had been initiated on highly active antiretroviral therapy (HAART) in 2005 (combination of stavudine, lamivudine with efavirenz), which he claimed to take conscientiously. Unfortunately, neither his CD4 count at time of HAART initiation nor his HIV-1 viral load at the time of this presentation was known.

A comprehensive clinical examination revealed no hepatomegaly and no splenomegaly; however, multiple enlarged lymph nodes were palpable, particularly in the neck. These lymph nodes were firm, non-tender and mobile. Upon sonographic examination of the abdomen, several enlarged para-aortic lymph nodes were demonstrated. The chest $X$-ray did not reveal any infiltrates suggestive of pulmonary involvement.

On first presentation to the dermatology clinic, he had a macrocytic anaemia with a haemoglobin level of $11.0 \mathrm{~g} / \mathrm{dl}$ and a mean corpuscular volume (MCV) of $113.7 \mathrm{fl}$ and

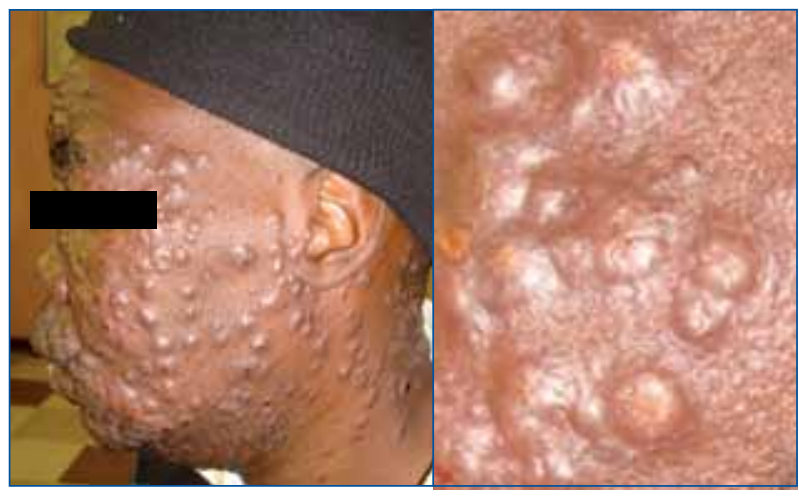

Figure $1 \mathrm{a}$ and $\mathrm{b}$ : Clinical appearance of skin lesions at time of presentation showing distribution and morphology of lesions with central umbilication.

mean corpuscular haemoglobin (MCH) of $39.8 \mathrm{pg}$. Iron studies revealed a low serum iron of $5.3 \mu \mathrm{mol} / \mathrm{l}$ (reference range 11.6 to $31.3 \mu \mathrm{mol} / \mathrm{l}$ ), decreased transferrin level of $1.3 \mathrm{~g} / \mathrm{l}$ (reference range 1.9 to $3.5 \mathrm{~g} / \mathrm{l}$ ) and low saturation of $16 \%$ (reference range of $20-50 \%$ ). The serum ferritin level, however, was markedly elevated at 1,680 $\mu \mathrm{g} / \mathrm{l}$ (reference range 11-306 $\mu \mathrm{g} / \mathrm{l})$, as determined and confirmed by serial dilutions.

Based on the morphology of the skin lesions, a differential diagnosis was made, and a skin biopsy was performed to distinguish between possible deep fungal infection, leprosy, sarcoidosis, mycosis fungoides and other conditions (Figure $2 a$ and $b)$. 


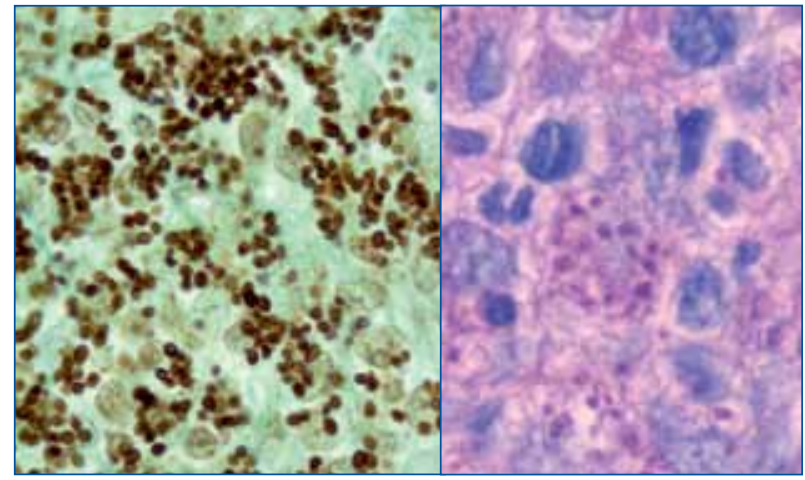

Figure 2 a: Grocott stain clearly showing yeast-like organisms in clusters, and Figure 2 b: Periodic Acid Schiff (PAS) stain showing yeast-like organisms.

The skin biopsy revealed numerous histiocytes, containing multiple clusters of PAS-positive, diastase-resistant inclusion bodies consistent with yeast-like organisms. No acid-fast organisms could be demonstrated in the sections. Based on the size and morphology of the organisms, a histological diagnosis of probable disseminated histoplasmosis was made. Although samples were submitted for culture, the fungus could not be grown, which is considered to be the gold standard of diagnosis.

The patient was initiated on oral itraconazole (400 mg daily) with significant clinical and haematological improvement, showing a recovery of his haemoglobin level to $14.1 \mathrm{~g} / \mathrm{dL}$ within six weeks.

\section{Discussion}

Histoplasma capsulatum is a dimorphic fungus associated with infection in immunocompromised patients. ${ }^{1-2} \mathrm{H}$. capsulatum var. capsulatum is endemic in some parts of the North and South America, ${ }^{2}$ as well as South Africa whereas $H$. capsulatum var. duboisii is found in Equatorial Africa, between the Sahara and Kalahari deserts. ${ }^{3}$ Despite this distribution, most cases described in South Africa have been associated with $H$. capsulatum var. capsulatum $^{4-5}$ as this organism is found endemically in caves in parts of the country ${ }^{4}$ as well as in association with settings rich in bird droppings. ${ }^{6}$ The disease entities associated with the two varieties are significantly different; patients with African histoplasmosis ( $H$. capsulatum var. duboisii) present most commonly with cutaneous, subcutaneous, bone and joint lesions and rarely with dissemination to the liver, spleen and gastrointestinal tract. ${ }^{3}$ Within the South African context, cutaneous manifestations of classical histoplasmosis (var. capsulatum) seems to be described. ${ }^{5}$

Disseminated histoplasmosis (DH) is most frequently described among patients with CD4+ T cell counts below 50 cells $/ \mathrm{mm}^{3},{ }^{1}$ and in endemic areas occur in $5 \%$ to $75 \%$ of AIDS patients, with mucocutaneous manifestations seen amongst $11 \%$ to $25 \%{ }^{2,5}$ Skin lesions can take a number of forms, from inflammatory folliculitis, rosacea-like eruptions and ulcers, to the nodular lesions ${ }^{2}$ described in this report.
Laboratory diagnosis is based on microscopy, histology, culture, antigen and antibody detection with varying sensitivities reported for each of these methods. ${ }^{1-2}$ Although reported sensitivities seem to be poor in general for histology, biopsies of skin lesions in HIV-1-infected patients have been cited to have sensitivities as high as $100 \% .{ }^{1}$ The differential diagnosis once yeasts are visualised in skin sections with the periodic acid Schiff (PAS) stain, include histoplasmosis, cryptococcosis and blastomycosis. The organisms may be distinguished based on morphological features, though this is difficult and requires an experienced histopathologist (Table I). Further confirmation can be obtained by performing additional special stains including the mucicarmine stain, which specifically stains the capsule. Classically, this stain will provide a positive result for encapsulated forms of Cryptococcus spp. and some subtypes of Blastomyces spp.; however, non-encapsulated forms will be negative as is Histoplasma spp. ${ }^{5}$

The gold standard for diagnosis is considered microbiological culture with conversion between mould to yeast phase with demonstration of organism-specific precipitins. ${ }^{8}$ The main limitation of this method remains the prolonged incubation periods required, which can be in excess of four weeks. ${ }^{9-10}$ Furthermore, culture seems to show limited sensitivity with false negative results obtained in as much as $20 \%$ of disseminated cases. ${ }^{8}$ Microbiological cultures are available at most academic centres in South Africa.

Antigen detection provides a more rapid result, but requires a high fungal burden to render a positive result. ${ }^{10}$ However, sensitivity seems to be higher among patients with AIDS as compared to patients with other underlying causes of immunosuppression. ${ }^{8}$ The sample of choice seems to be urine, as it shows improved sensitivity when compared to serum samples. ${ }^{9,11,12}$ Bronchoalveolar lavage fluid may also be used in cases with pulmonary localisation..$^{13}$ It is often also utilised in monitoring treatment response in patients with disseminated disease ${ }^{8,10}$ and monitor for relapse. ${ }^{8}$ Antigen detection is not available locally. ${ }^{14}$

Serological detection of antibodies specific to Histoplasma serves as an alternative diagnostic tool. Pitfalls with this

Table I: Morphological characteristics of yeast forms for several mycoses

\begin{tabular}{|l|l|l|l|l|}
\hline & $\begin{array}{l}\text { H. capsulatum } \\
\text { var. capsulatum }\end{array}$ & $\begin{array}{l}\text { H. capsulatum } \\
\text { var. duboisii }\end{array}$ & Cryptococcus & Blastomyces \\
\hline Yeast size & $2-4 \mu \mathrm{m}^{3}$ & $12-15 \mu \mathrm{m}^{3}$ & $3.5-8 \mu \mathrm{m}^{7}$ & $8-15 \mu \mathrm{m}^{7}$ \\
\hline Shape & Oval $^{1}$ & Ovoid $^{1}$ & Oval $^{7}$ & Spherical $^{3}$ \\
\hline Budding & $\begin{array}{l}\text { Narrow-based } \\
\text { budding }\end{array}$ & $\begin{array}{l}\text { Narrow-based } \\
\text { budding }\end{array}$ & $\begin{array}{l}\text { Single budding } \\
\text { with narrow } \\
\text { neck }\end{array}$ & $\begin{array}{l}\text { Broad-based }^{7} \\
\text { budding }^{3}\end{array}$ \\
\hline Cell wall & $\begin{array}{l}\text { Thin walled } \\
\text { Rigid }\end{array}$ & Thick walled & $\begin{array}{l}\text { Thick and } \\
\text { mucoid } \\
\text { Capsule- } \\
\text { deficient (CD) } \\
\text { forms }\end{array}$ & Thick capsule \\
\hline $\begin{array}{l}\text { Mucicarmine } \\
\text { stain }^{5}\end{array}$ & Negative & Negative & $\begin{array}{l}\text { Positive } \\
\text { Negative in CD } \\
\text { forms }\end{array}$ & $\begin{array}{l}\text { Positive } \\
\text { Negative in CD } \\
\text { forms }\end{array}$ \\
\hline
\end{tabular}


testing modality include a delay in seroconversion to positivity of about one month, which may be further delayed in immunocompromised individuals. ${ }^{8}$ Seroconversion to negative results following successful treatment is also delayed for several years. Furthermore, cross-reaction with other fungal pathogens, including paracoccidioidomycosis, blastomycosis, aspergillosis and rarely coccidioidomycosis has also been described. ${ }^{8,10}$

Historically, skin tests could be performed but showed a high false positivity rate due to exposure and cross-reaction with other fungal pathogens ${ }^{8,9}$ as well as false positivity among proven cases of disseminated histoplasmosis. ${ }^{8}$

Although very promising, molecular testing is not commercially available as yet. ${ }^{9}$ However, various in-house PCRs are described showing promise to improve both sensitivity and turnaround time for positive identification of histoplasma. ${ }^{9,15,16}$

Hyperferritinaemia (serum ferritin levels exceeding 1,500 $\mu \mathrm{g} / \mathrm{L}$ ) has been associated in the past with $\mathrm{DH} .{ }^{17}$ Various authors have alluded to ferritin levels in excess of 10,000 $\mu \mathrm{g} / \mathrm{L}$, as a highly specific marker for $\mathrm{DH} .{ }^{17}$ In the current clinical case, the patient did present with a markedly elevated level, although much lower than described in these reports. Hyperferritinaemia seems to have a significantly different epidemiology in South Africa, where the most common infectious cause seems to be disseminated infection with Mycobacterium tuberculosis. ${ }^{18}$

The Infectious Diseases Society of America (IDSA) published treatment guidelines in 2007 for the treatment of histoplasmosis. The treatment regimens are determined by disease severity as well as site of infection, associated organ damage and the patient's immune status. ${ }^{19}$ In this clinical case of probable disseminated histoplasmosis, the treatment of choice would be a two week course of intravenous amphotericin B (0.7-1 mg/kg/day). Thereafter, the patient should be treated with itraconazole $600 \mathrm{mg}$ for three days, and $400 \mathrm{mg}$ there-after, in divided doses for at least 12 months. If the degree of immunosuppression cannot be improved, lifelong therapy is advocated. ${ }^{19}$

Histoplasmosis, like most opportunistic infections, can present with a myriad of clinical features which can complicate early diagnosis. Although not as prevalent as in other parts of the world, it should always be considered as part of the differential diagnosis, especially among severely immunocompromised individuals.

\section{References}

Loulergue P, Bastides F, Baudouin V, et al. Literature Review and Case Histories of Histoplasma capsulatum var. duboisii Infections in HIV-infected Patients. Emerg Inf Dis 2007; 13(11): 1647-1652

2. Angius A, Viviani M, Muratori S, Cushini M, Brignolo L, Alessi E. Disseminated histoplasmosis presenting with cutaneous lesions in a patient with acquired immunodeficiency syndrome. JEADV 1998; 10: 182-185

3. Vieira R, Botelho M, Lima C, Laxaro A, Martins M. Intra-abdominal abscess: A clinical manifestation of African histoplasmosis. J de Myco Medicinale 2009; 19: 134-137

Gugnani H. Histoplasmosis in Africa: a review. Indian J Chest Dis Allied Sci 2000; 42(4): 271-277

Ramdial P. Mosam A, Dlova N, Satar N, Aboobaker J, Singh S. Disseminated cutaneous histoplasmosis in patients infected with human immunodeficiency virus. J Cutan Pathol 2002; 29: 215-225

6. Taylor M, Granados J, Toriello C. Biological and sociocultural approaches of histoplasmosis in the State of Guerrero, Mexico. Mycoses 1996; 39(9): 375-379

7. Walsh T, Larone D, Schell W, Mitchell T. Histoplasma, Blastomyces, Coccidioides and Other Dimorphic Fungi Causing Systemic Mycoses. In: Murray P, Baron E, Jorgensen J, Pfaller M, Yolken R, eds. Manual of Clinical Microbiology. Washington DC: ASM Press; 2003

8. Wheat L. Current diagnosis of histoplasmosis. Trends in Microbiol 2003; 11(10): 488-494

9. Kauffman C. Histoplasmosis: a Clinical and Laboratory Update. CMR 2007; 20(1): 115-132

10. Wheat L. Histoplasmosis: a review for clinicians from non-endemic areas. Mycoses 2006; 49: 274-282

11. Williams $B$, Fojtasek $M$, Connolly-Stringfield $P$, Wheat J. Diagnosis of histoplasmosis by antigen detection during an outbreak in Indianapolis. Ind Arch Pathol Lab Med 1994; 118(12): 1205-1208

12. Wheat $L$, Kohler R, Tewani R. Diagnosis of Disseminated Histoplasmosis by Detection of Histoplasma capsulatum Antigen in Serum and Urine Specimens. N Engl J Med 1986; 314: 83-88

13. Wheat L, Connolly-Stringfield P, Baker R, Curfman M, Eads M, Israel K, et al. Disseminated Histoplasmosis in the Acquired Immune Deficiency Syndrome: Clinical Findings, Diagnosis and Treatment, and Review of the Literature. Medicine 1990; 69(9): 361-374

14. Govender N. HN-associated opportunistic fungal infections: A guide to using the clinical microbiology laboratory. SAJHIVM 2007; Spring:18-23

15. Maubon D, Simon S, Aznar C. Histoplasmosis diagnosis using a polymerase chain reaction method. Application on human samples in French Guiana, South America. Diagn Microbiol Infect Dis 2007; 58: 441-444

16. Komori T, Sano A, Yarita K, Kitagawa T, Kamei K, Nishimura K. Phylogenetic Analysis of Histoplasma capsulatum Based on Partial Sequence of the D1/Dr Region of the 28 rRNA Gene. Jpn J Med Mycol 2005; 46: 291-295

17. Kirn D, Fredericks D, McCutchan J, Stiles D, Shuman M. Marked elevation of the serum ferritin is highly specific for disseminated histoplasmosis in AIDS. AIDS 1995; 9(10): 1204-1205

18. Visser A, Van der Vyver A. Severe hyperferritinaemia in Mycobacterium tuberculosis infection. Clin Infect Dis 2010 (in press)

19. Wheat L, Freifeld A, Kleiman M, et al. Clinical Practice Guidelines for the Management of Patients with Histoplasmosis: 2007 Update by the Infectious Disease Society of America. Clin Infect Dis 2007; 45: 807-825 